\title{
THE EFFECT OF THE AQUEOUS EXTRACT OF THE LEAVES OF Boerhavia diffusa Linn. ON SEMEN AND TESTICULAR MORPHOLOGY OF MALE WISTAR RATS
}

\author{
*ADENUBI, O.T. ${ }^{1}$, RAJI, Y. ${ }^{2}$, AWE, E.O. ${ }^{3}$ \& MAKINDE, J. M. ${ }^{4}$ \\ 1Department of Veterinary Physiology and Pharmacology, College \\ of Veterinary Medicine, University of Agriculture, P.M.B 2240, \\ Alabata, Abeokuta, Ogun State, Nigeria. \\ 2Department of Physiology, College of Medicine, University of \\ Ibadan, Nigeria. \\ 3Department of Pharmacology and Therapeutics, College of Health \\ Sciences, Ladoke Akintola University of Technology, Ogbomoso, \\ Nigeria. \\ ${ }^{4}$ Department of Pharmacology and Therapeutics, College of \\ Medicine, University of Ibadan, Nigeria. \\ *bukioguns@yahoo.com
}

\begin{abstract}
The effect of aqueous leaf extract of Boerhavia diffusa plant on the semen and testicular morphology of male Wistar rats was investigated. Thirty five rats were divided into seven groups of five animals each (Groups I-VII) with group I serving as the control. Distilled water $(0.5 \mathrm{mls})$ was administered orally to rats in Group I (Control), while rats in the remaining six experimental groups (II-VII) were dosed orally with 50,100 and $150 \mathrm{mg} / \mathrm{kg}$ of $2.4 \%$ aqueous extract of $B$. diffusa for 60 days and then euthanized immediately (Grps II, IV \& VI) or allowed to recover for one week before euthanasia (Grps III, V \& VII). The serum testosterone level, weights and histopathology of the testes, epididymes and seminal vesicles were determined, and the spermatozoa from the cauda epididymes of the groups were studied. Data were compared using Man-whitney's test and analysis of variance (ANOVA). There was no significant difference in the serum testosterone level between treated rats and control. The weights of the testes, epididymes and seminal vesicles were however significantly $(\mathrm{P}<0.05)$ decreased in treated rats compared with the control. Sperm motility and sperm count decreased significantly $(P<0.05)$ also in the treated rats compared with the control. In addition, the sperm live-dead ratio decreased significantly $(\mathrm{P}<0.05)$ in rats treated with 100 and $150 \mathrm{mg} / \mathrm{kg}$ of the extract (Grps IV-VII) compared with the control. Histopathology of the testes of treated rats revealed marked degeneration of germinal epithelia with spermiostasis. This result suggests that aqueous extract of $B$. diffusa produced adverse effects in semen and testicular morphology of the rats.
\end{abstract}

Key words: B. diffusa, semen morphology, testicular morphology.

\section{INTRODUCTION}

Boerhavia diffusa Linn. (Family: Nyctaginaceae) is a plant known for its medicinal properties, employed in folkloric medicine in Nigeria, and Ayurvedic medicine system of India (Dhar et al., 1968). It is a low growing, spreading vine with a tuberous tap root widely distributed in the tropical, subtropical and temperate regions of the world (Sahu et al., 2008). The plant is consumed as vegetable as it is believed to be a rich source of vitamins, minerals, protein and carbohydrate (Cho et al., 2004). It has been shown to contain a large number of compounds such as flavonoids, saponins, steroids and alkaloids (Ujowundu et al., 2008).

Traditionally, the plant has been evaluated for its hepatoprotective, anti-diabetic, diuretic, anti-inflammatory, antibacterial, antiviral and cancer chemopreventive properties (Rawat et al., 2008; Pari et al., 2008). In rats, aqueous extract of thinner roots of $B$. diffusa at a dose of $2 \mathrm{ml} / \mathrm{kg}$ caused a reduction in the levels of serum glutamate oxaloacetate transaminase and serum glutamate pyruvate transaminase when compared with control rats. This suggested that the plant protects against hepatic injury in rats
(Rawat et al., 2008). The anti-diabetic property of $B$. diffusa leaf extract was also studied in normal and alloxan induced diabetic rats and found to significantly decrease blood glucose and significantly increase plasma insulin levels (Pari et al., 2008). This was thought to be due to rapid phosphorylation of glucose by hexokinase causing increased utilization of glucose for energy production. This seems to suggest that $B$. diffusa extract may have a mechanism of action similar to that of sulphonylureas (Baquer et al., 1998).

Recent studies have also suggested the anti-tumor activity of $B$. diffusa (Milic, 2007). The inhibition of tumorigenesis by the plant extract was thought to be due to the prevention of the formation of active carcinogens from their precursors or by augmenting detoxification process through free radical scavenging mechanism (Bharali et al., 2003). The alkaloids; Boeravinones $\mathrm{G}$ and $\mathrm{H}$ isolated from $B$. diffusa have also been reported to inhibit breast cancer resistant proteins (Diestra et al., 2002).

Studies have established delayed toxicities of anti-tumor chemotherapy on long term survivors. These include depletion of the germinal epithelial lining of the seminiferous tubules with increase number of germinal cell apoptosis, decreased sperm counts with increase percentage of tail and head abnormalities and increases in both pre and post-implantation tissue (Daleck et al., 1995; Codrington et al., 2007; Farida et al., 2007). In the light of the potential role of $B$. diffusa as an anti-tumor agent and its current use in Ayurvedic medicine, a further toxicity test on the plant especially during prolonged administration is essential. The aim of this study was to investigate the effect of oral administration of the aqueous extract of $B$. diffusa for sixty days on the semen and testicular morphology in male Wistar rats.

\section{MATERIALS AND METHODS}

Animals: Thirty five adult male Wistar rats (mean body weight: $174.5 \pm 3.33 \mathrm{~g}$ ) were used for this study. They were housed in metal cages, at ambient room temperature, with a controlled photoperiod of 12 hours. The rats were fed pelleted grower mash (Vital feeds Limited, Ibadan, Nigeria) and water provided adlibitum. The experimental protocols conformed to the Institutional Animal Ethics Committee's guidelines.

Preparation of the extract: The leaves of $B$. diffusa were shade dried for two weeks, pulverized to powder, finely sieved and soaked in 2 litres of distilled water for 24 hours, after which it was filtered using Whatman filter paper No. 2 (Whatman International Ltd, England). Thereafter, the filtrate was freeze-dried and the percent yield was $2.4 \%$. Aliquot portions of the extract were weighed and dissolved in distilled water (at room temperature) for use on each day of the experiment.

Experimental Procedure: The rats were randomly divided into seven groups of five animals each (Groups I-VII). They were weighed before the commencement of the study and then weekly until the study was terminated. Distilled water $(0.5 \mathrm{mls})$ was administered to rats in Group I orally once daily for 60 days while rats in groups II, IV and VI were dosed with 50, 100 and $150 \mathrm{mg} / \mathrm{kg}$ respectively of the $2.4 \%$ aqueous extract of Boerhavia diffusa leaves orally for 60 days and euthanized thereafter. Rats in groups III, V and VII were also dosed 50, 100, and 150mg/kg aqueous 
extract of $B$. diffusa leaves respectively for 60 days but allowed to recover for one week before they were euthanized. All animals were euthanized by ether inhalation followed by cervical dislocation.

Sampling: Prior to euthanasia, the rats in each group were bled through the orbital sinus using capillary tubes into sterile containers and the samples sent to the laboratory for the determination of serum testosterone. Immediately after euthanasia, a ventral midline abdominal incision was made using surgical blade size 14 (Meiyi, Huaiyin, China). The epididymes, seminal vesicles and testes were identified, removed, cleared of fat and weighed. Semen was then collected by incising and squeezing the cauda epididymis of each animal on a clean glass slide to determine the progressive sperm motility, sperm live-dead ratio and sperm count according to the method of Oyeyemi et al., (1996). Tissues were subsequently preserved in Bouins fluid for histopathological evaluation.

Serum testosterone, sperm count, testicular, seminal vesicles and epididymal weight were expressed as mean \pm standard error of mean (SEM). The progressive sperm motility and sperm live-dead ratio were expressed as percentages and presented as median and range. Since the data were not normally distributed, they were compared using Man-Whitney's test and analysis of variance (ANOVA). Test of significance was determined using the Wilcoxon sign rank test and post-hoc analysis was done using Duncan's multiple range tests. All $p$ - value less than 0.05 were considered significant.

\section{RESULTS}

The progressive sperm motility was significantly $(P<0.05)$ decreased in the treated rats when compared with the control. This decrease was found to be dose dependent. In addition, the progressive sperm motility was lower in the groups allowed to recover for one week (Groups III, V and VII) when compared with those euthanized immediately in Groups II, IV and VI (Table 1).
TABLE 1. EFFECT OF DIFFERENT DOSES OF AQUEOUS EXTRACT OF Boerhavia diffusa L. LEAVES ON PROGRESSIVE SPERM MOTILITY OF MALE WISTAR RATS.

\begin{tabular}{lll}
\hline \multicolumn{1}{c}{ Groups } & $\begin{array}{l}\text { Median } \\
(\%)\end{array}$ & $\begin{array}{l}\text { Range } \\
(\%)\end{array}$ \\
\hline Group I (Control) & 95 & $90-95$ \\
Group II (50mg/kg treated) & $90^{*}$ & 90 \\
Group III (50mg/kg recovery) & $75^{*}$ & $60-90$ \\
Group IV (100mg/kg treated) & $70^{*}$ & $50-80$ \\
Group V (100mg/kg recovery) & $55^{*}$ & $40-60$ \\
Group VI (150mg/kg treated) & $55^{*}$ & $50-60$ \\
Group VII (150mg/kg recovery) & $40^{*}$ & $40-60$ \\
\hline $\mathrm{n}=5, \quad{ }^{*} \mathrm{P}<0.05$ & &
\end{tabular}

The sperm live-dead ratio did not differ between the control rats and rats dosed $50 \mathrm{mg} / \mathrm{kg}$ of the extract (Groups II and III). However, it decreased significantly $(P<0.05)$ in the rats that were treated with 100 and $150 \mathrm{mg} / \mathrm{kg}$ (Groups IV-VII) of the extract compared with the control (Table 2).

The weight of the testes, epididymes and seminal vesicles were significantly $(P<0.05)$ decreased in treated rats compared with the control (Table 3). However, the weight of the testes, epididymes and seminal vesicles did not differ significantly between Groups III, V and VII that were allowed to recover and those in Groups II, IV and VI euthanized immediately.

TABLE 2. EFFECT OF DIFFERENT DOSES OF AQUEOUS EXTRACT OF Boerhavia diffusa ON SPERM LIVE-DEAD RATIO OF MALE WISTAR RATS

\begin{tabular}{lll}
\hline \multicolumn{1}{c}{ Groups } & $\begin{array}{l}\text { Median } \\
(\%)\end{array}$ & Range (\%) \\
\hline Group I (Control) & 96.5 & $95-98$ \\
Group II (50mg/kg treated) & 96.5 & $95-98$ \\
Group III (50mg/kg recovery) & 96.5 & $90-98$ \\
Group IV (100mg/kg treated) & $87.5^{\star}$ & $80-95$ \\
Group V (100mg/kg recovery) & $90^{*}$ & $80-95$ \\
Group VI (150mg/kg treated) & $90^{*}$ & $90-95$ \\
Group VII (150mg/kg recovery) & $85^{\star}$ & $80-90$ \\
\hline $\mathrm{n}=5,{ }^{*} \mathrm{P}<0.05$ & &
\end{tabular}

TABLE 3. THE EFFECT OF DIFFERENT DOSES OF THE AQUEOUS EXTRACT OF Boerhavia diffusa L. LEAVES ON THE WEIGHTS OF ORGANS OF MALE WISTAR RATS ( IN GROUPS II, IV AND VI ) AND (GROUPS III, VI AND VII).

\begin{tabular}{llll}
\hline \multicolumn{1}{c}{ Groups } & $\begin{array}{l}\text { Weight of } \\
\text { epididymis (g) }\end{array}$ & $\begin{array}{l}\text { Weight of } \\
\text { seminal } \\
\text { vesicle (g) }\end{array}$ & $\begin{array}{l}\text { Weight of } \\
\text { testis (g) }\end{array}$ \\
\hline Group I (Control) & $0.26 \pm 0.06$ & $0.80 \pm 0.16$ & $1.09 \pm 0.06$ \\
Group II (50mg/kg treated) & $0.23 \pm 0.02^{*}$ & $0.72 \pm 0.22^{*}$ & $0.95 \pm 0.20^{*}$ \\
Group III (50mg/kg recovery) & $0.24 \pm 0.03^{*}$ & $0.73 \pm 0.25^{*}$ & $1.02 \pm 0.23^{*}$ \\
Group IV (100mg/kg treated) & $0.20 \pm 0.04^{*}$ & $0.70 \pm 0.15^{*}$ & $0.90 \pm 0.10^{*}$ \\
Group V (100mg/kg recovery) & $0.22 \pm 0.03^{*}$ & $0.70 \pm 0.17^{*}$ & $0.94 \pm 0.15^{*}$ \\
Group VI (150mg/kg treated) & $0.20 \pm 0.04^{*}$ & $0.66 \pm 0.34^{*}$ & $0.82 \pm 0.08^{*}$ \\
Group VII (150mg/kg recovery) & $0.21 \pm 0.02^{*}$ & $0.69 \pm 0.28^{*}$ & $0.88 \pm 0.43^{*}$ \\
\hline $\mathrm{n}=5,{ }^{*} \mathrm{P}<0.05$ & & &
\end{tabular}

There was no significant difference in the serum testosterone level in treated rats compared with the control (Figs. 1 \& 2). However there was a significant $(P<0.05)$ dose dependent decrease in the sperm count of the treated rats compared with the control (Figs. 3 $\& 4)$. 


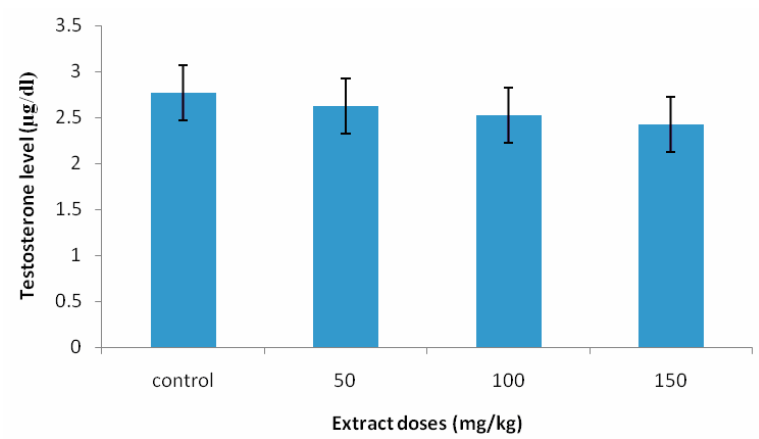

FIG. 1. EFFECT OF DIFFERENT DOSES OF AQUEOUS EXTRACT OF Boerhavia diffusa L. LEAVES ON SERUM TESTOSTERONE LEVEL OF MALE WISTAR RATS.

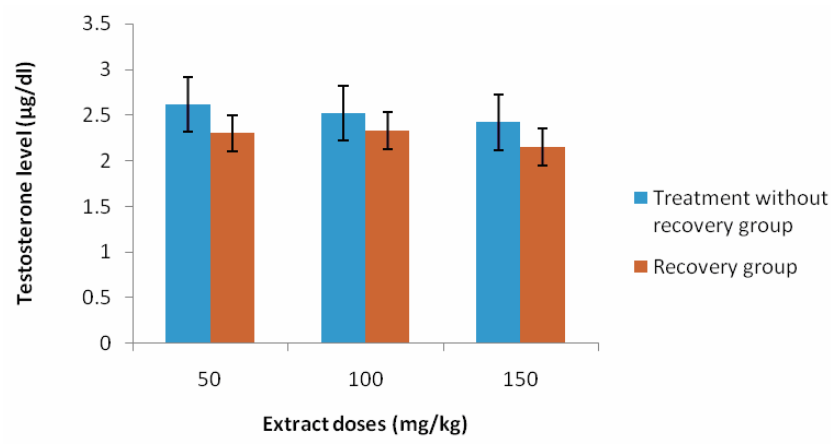

FIG. 2. EFFECT OF DIFFERENT DOSES OF AQUEOUS EXTRACT OF Boerhavia diffusa L. LEAVES ON THE SERUM TESTOSTERONE LEVEL OF MALE WISTAR RATS TREATED IN GROUPS ALLOWED TO RECOVER AND THOSE EUTHANISED.

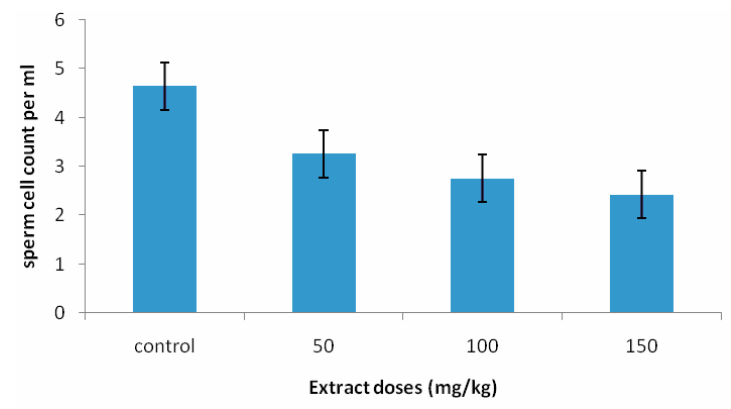

FIG 3. EFFECT OF DIFFERENT DOSES OF AQUEOUS EXTRACT OF Boerhavia diffusa L. LEAVES ON SPERM COUNT OF MALE WISTAR RATS.

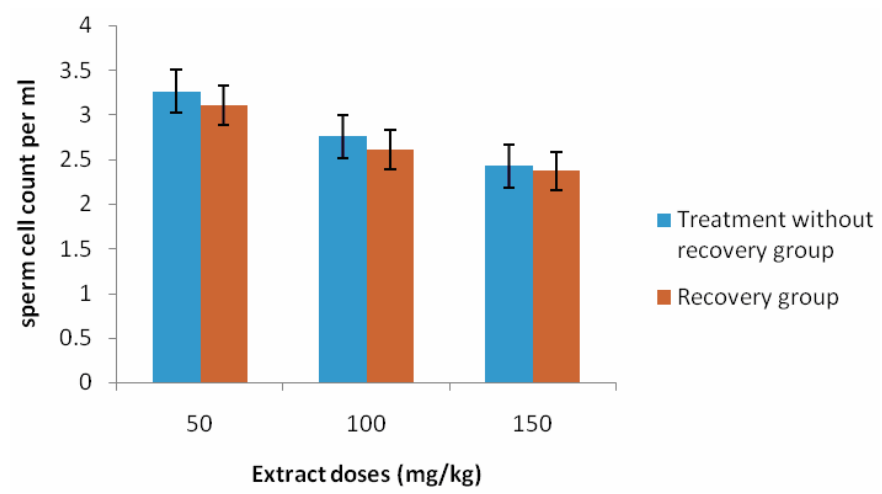

FIG 4. EFFECT OF DIFFERENT DOSES OF AQUEOUS EXTRACT OF Boerhavia diffusa L. LEAVES ON THE SPERM COUNT OF MALE WISTAR RATS TREATED IN GROUPS II ALLOWED TO RECOVER AND THOSE EUTHANISED. 
Histopathological examination of the testes of the male rats treated with aqueous extract of $B$. diffusa revealed marked degeneration the germinal epithelia in the seminiferous tubules with spermiostasis (Fig. 5A) compared to the control (Fig 5B).

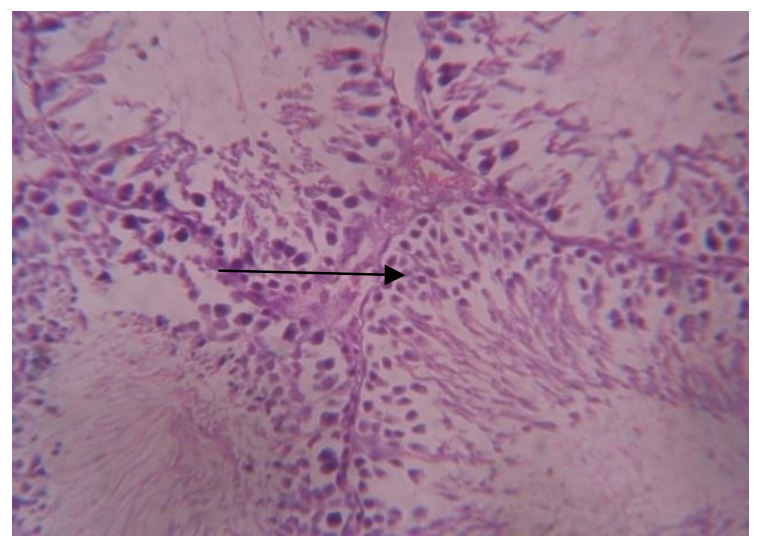

\section{FIG. 5A. PHOTOMICROGRAPH OF THE TESTIS OF THE MALE WISTAR RAT TREATED WITH 100MG/KG OF THE EXTRACT (GROUP IV) SHOWING AREAS OF DEGENERATION AND NECROSIS OF THE GERMINAL EPITHELIAL CELLS IN THE SEMINIFEROUS TUBULES. (BLACK ARROW INDICATES SPERMIOSTASIS. H \& E STAIN X 250).}

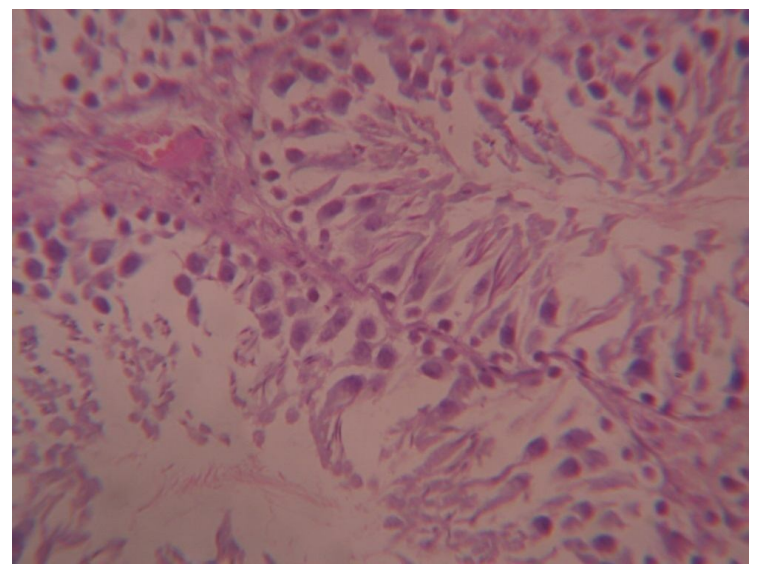

\section{FIG. 5B. PHOTOMICROGRAPH OF THE TESTIS OF THE CONTROL (GROUP I) MALE WISTAR RAT. (H \& E STAIN X250).}

\section{DISCUSSION}

Oral administration of graded doses of aqueous extract of Boerhavia diffusa L. leaves for sixty days to male Wistar rats caused dose dependent decreases in sperm count, progressive sperm motility and sperm live-dead ratio. Similarly, there were dose dependent decreases in the weight of the epididymes, seminal vesicles and testes with associated degeneration of the germinal epithelia of the seminiferous tubules.

B. diffusa has been reported to have a wide safety margin. The L. $D_{50}$ of the aqueous extract of the leaf is above $2000 \mathrm{mg} / \mathrm{kg}$ and doses ranging from $50 \mathrm{mg} / \mathrm{kg}$ to $2000 \mathrm{mg} / \mathrm{kg}$ had been used in clinical trials (Orisakwe et al., 2003). In this study, three doses; 50, 100 and $150 \mathrm{mg} / \mathrm{kg}$ were tested because chronic administration of these doses were reported to produce a dose-dependent reduction in blood glucose in streptozotocin-induced non-insulin dependent diabetes mellitus in rats (Rao et al., 2004) . However, the study did not determine whether the doses also produced toxic side effects in the rats. The result of this present study suggested that chronic administration of $B$. diffusa plant is harmful to the male reproductive organs.

Testosterone is secreted from cholesterol by the Leydig cells under the influence of Luteinizing hormone (McLachlan et al.,
1996). It is responsible for the establishment of secondary sexua characteristics and the promotion of spermatogenesis (Orth, 1993). The release of testosterone into circulation is controlled by gonadotropin releasing hormone (GnRH) and constant exposure to $\mathrm{GnRH}$ results in a negative feed back inhibiting further release of gonadotropins thereby causing a reduction in the serum testosterone (Rea et al., 1986). In this study, administration of aqueous extract of $B$. diffusa $L$. leaves for sixty days to male Wistar rats resulted in a decrease in serum testosterone levels in the rats.

Sperm motility is one of the most important predictors of fertility. The main energy source for motile spermatozoa is Adenosine triphosphate (ATP). This is released by the breakdown of fructose secreted by the seminal vesicles. Reduced ATP production and/or reduced ATP levels via ATPase hydrolysis results in insufficient energy and poor sperm motility (Tocharus et al., 2005; Yakubu et al., 2007). In this study, the dose dependent decrease in the sperm motility of the male Wistar rats might be associated with the hypoglycaemic effect of the extract causing decreases in the level of the fructose in the seminal vesicles (Chude et al., 2001). Although the serum glucose and seminal fructose concentrations were not determined in this study, it is logical to assume that the 
decrease in sperm motility is due to the altered carbohydrate metabolism. The decrease in the sperm live-dead ratio and sperm count in the rats may also be related to the decreased serum testosterone level as testosterone is involved in the promotion of spermatogenesis (Orth, 1993).

A dose dependent decrease in the weights of the epididymes, seminal vesicles and the testes with associated degeneration of the germinal epithelia and spermiostasis were also observed in this study. This result is consistent with a study evaluating subchronic toxicity of aqueous extract of $B$. diffusa $L$. leaves in which a non-statistically significant dose dependent decrease in testicular weight of Wistar rats was reported (Oyeyemi et al., 1996). In addition, the histopathological findings suggested that the toxic effect of the plant may be irreversible since the groups that were allowed to recover did not show any improvement compared to the groups that were not allowed to recover. Although, it may be that the one week allowed for the rats to recover may be too short to observe any improvement. The histopathological findings, sperm and testicular morphology in these rats were similar to that observed following prolonged use of anti-tumor drugs (Yakubu et al., 2007).

In conclusion, this study showed that oral administration of aqueous extract of $B$. diffusa $L$. leaves for sixty days to male Wistar rats decreased the sperm count, progressive sperm motility, sperm live-dead ratio and caused degeneration of the germinal epithelia of the testes. There is therefore the need to further investigate the mechanism for the anti-fertility induced by the aqueous extract of $B$. diffusa $L$. leaves.

\section{ACKNOWLEDGEMENT}

We thank Dr. O. L. Ajayi for reading and interpreting the histopathology section of this work.

\section{REFERENCES}

Baquer N. Z., Gupta D, Raju J. (1998). Regulation of metabolic pathways in liver and kidney during experimental diabetes: effects of antidiabetic compounds. Indian Journal of Clinical Biochemistry 13: $63-80$.

Bharali, R., Azad, M. R., Tabassum, J. (2003). Chemopreventive action of Boerhavia diffusa on DMBA-induced skin carcinogenesis in mice. Indian Journal of Physiology and Pharmacology 47(4): 459-464.

Cho, E, Seddom J, Ronser, B, Willet, W., Hankison, S. (2004). Prospective study of intake of fruits, vegetables, vitamins and carotenoids and related musclopathy. Archives of Opthalmology 122: 883-892.

Chude, M. A. Orisakwe O. J, Afonne OJ, Gamaniel KS, Vongtau $\mathrm{OH}$, Obi E. (2001). Hypoglycaemic effect of the aqueous extract of Boerhaavia diffusa leaves. Indian Journal of Pharmacology 33: 215-216.

Codrington, A. M., Hales, B. F., Robaire, B. (2007). Exposure of male rats to cyclophosphamide alters the chromatin structure and basic proteome in spermatozoa. Human Reproduction 22(5): 1431-1442.

Daleck, C. R., Francheschini, P. H., Padilha Filho, J. G. (1995). Analise histological de testiculose semen de caes submedicos a administracao de vincristina. Brazilian Journal of Veterinary Research and Animal Science 32(1):51-56.
Dhar, M. L., Dhar, M. M., Dhawan, B. N., Mehrotra, B. N., Ray, C. (1968). Screening of Indian plants for biological activity. Indian Journal of Experimental Biology 6 (Part 1):232-247.

Diestra, J. E., Scheffer, G. L., Catal, I., Maliepaard, M., Schellens, J. H., Scheper, R. J. (2002). Frequent expression of the multi-drug resistance associated protein BCRP/MXR/ABCP/ABCG2 in human tumours detected by the BXP-21 monoclonal antibody in paraffinembedded material. Journal of Pathology 198:213-219.

Farida, V., Geraldine, D., Barbara, F., Robaire, B. (2007). Effects of the chemotherapeutic agents for Non-Hodgkin lymphoma, Cyclophosphamide, Doxorubicin, Vincristine and Prednisone (CHOP) on the male rat reproductive system and progeny outcome. Journal of Andrology 28(4): 578.

Kenney, L. B., Laufer, M. R., Grant, F. D., Grier, H., Diller, L. (2001). High risk of infertility and long term gonadal damage in males treated with high dose cyclophosphamide for sarcoma during childhood. Cancer 91:613-621.

McLachlan, R. I., Wreford, N. G., O'Donnell, L, de Kretser, D. M., Robertson, D. M. (1996). The Endocrine Regulation of Spermatogenesis: Independent Roles for Testosterone and FSH. Journal of Endocrinology 148:1-9.

Milic, D. N. (2007). Biological and Phytochemical studies on Boerhavia diffusa. Ph.D thesis Universita De gli Studi Di Napoli Federico II, Italy: 149 .

Orisakwe, O. E., Afonne, O. J., Chude, M. A., Obi, E., Dioka, C. E. (2003). Sub-chronic toxicity studies of the aqueous extract of Boerhavia diffusa leaves. Journal of Health Science 49(6): 444447.

Orth, J. M. (1993).Cell and Molecular biology of the testis (eds Desjardins, C, Ewing). University Press, New York: 3-43.

Oyeyemi, M. O., Akusu, M. O., Olaoye, M. O., Omobowale, O. T. (1996). Effect of frequent ejaculation on the semen characteristic of West African Dwarf Bucks. Troical Veterinarian 14: 71-75.

Pari, L., Satheesh., M. A. (2008). Antidiabetic activity of Boerhaavia diffusa L.: effect on hepatic key enzymes in experimental diabetes. Journal of Ethnopharmacology 91: 109113.

Rao, K. N., Krishna, M. B., Srinivas, N. (2004). Effect of chronic administration of Boerhaavia diffusa Linn. leaf extract on experimental diabetes in rats. Tropical Journal of Pharmaceutical Research 3(1): 305-309.

Rawat, A. K. S., Mehrotra, S., Tripathi, S. K., Shome, U. 2008. Hepatoprotective activity of Boerhavia diffusa L. roots - a popular Indian ethnomedicine. Journal of Ethnopharmacology 56: 61-66.

Rea, M. A., Marshall, G. R., Weinbaner, G. F., Nieshschlag, E. (1986). Journal of Endocrinology 108: 101-103.

Sahu, A. N., Damiki, L., Nilanjan, G., Dubey, S. (2008). Phytopharmacological review of Boerhaavia diffusa Linn. (Punarnava). Pharmacognosy Review 4 (Suppl 2): 14-22.

Tocharus, C., Jeenapongsa, R., Teakthong, T., Smitasiri, Y. (2005). Effects of long-term treatment of Butea superb on sperm motility and concentration. Naresuan University Journal 13(2): 11 17. 
Ujowundu, C. O., Igwe, C. U., Enemor, V. H., Nwaogu, L. A. Okafor, O. E. (2008). Nutritive and Anti-nutritive properties of Boerhavia diffusa and Commelina nudiflora leaves. Pakistan Journal of Nutrition 7(1): 90-92.
Yakubu, M. T., Akanji, M. A., Oladiji, A. T. (2007). Male sexual dysfunction and methods used in assessing medicinal plants with aphrodisiac potentials. Pharmacogonosy Review 1 (Suppl 1): 4956. 